\title{
Crystal growth competition, a key for crystallography emergence in Benin
}

Marielle Yasmine Agbahoungbata ${ }^{1}$, Wilfried Sènami Kangbodé ${ }^{1}$, Albert Sourou Sidoine Bonou ${ }^{1}$, Etienne Vidjannagni Sagbo ${ }^{1}$

${ }^{1}$ Department Of Chemistry / University Of Abomey-Calavi, Cotonou, Benin E-mail: hounmar@gmail.com

2014 was the International Year of Crystallography celebrated in many countries throughout the world. This event was also held at University of Abomey-Calavi (Republic of Benin) thanks to the Benin section of West-African Society of Chemistry (SOACHIM) and the support from UNESCO and IUCr. Many activities such as lectures, oral and poster presentation were done from November 13rd to 14th, 2014. The main and great activity was the crystal growth competition for student at the first and second degree in scientific and technology fields. Fifty students participated to the competition which consists in growing $\mathrm{NaCl}$ and Alum crystals. The best crystals were selected at the end and sent to UNESCO for participation of Benin to the world competition. This experience enables the organizing committee of which I was a member to discover three major things: the real state of crystallography in our country, the keen interest that students showed for crystal growth competition and the excellent opportunity given by this activity to be an attraction and a motivation for young student to do crystallography sciences. Indeed, when the call for applications to crystal growth competition is opened, very few candidates applied. None of them was able to describe a crystal or to say the crystal meaning in his mother tongue. Moreover, they had no knowledge about practice applications of crystallography. However, thanks to the conferences we organized around the IYCr brochure, the number of applicant has increased very quickly. The competition held from October 1st to November 13rd, about 45 days during which candidates worked assiduously and with great motivation. "An enjoying experience that I would like to resume" was the main testimony we received at the end of event. In addition, many of these students are currently in Bachelor degree of fundamentals sciences. All this allow us to propose a program on the crystal growth competition extended to young students and young researchers taking into account playful and cultural aspects. Since there is no development without qualify human resources which strongly depend on the basic education, we believe that the program on crystal growth competition we propose (scientific, playful and cultural) will greatly contribute to the development of crystallography sciences in Benin.

Keywords: Crystal growth competition, Benin 